\title{
Subcortical infarction resulting in acquired stuttering
}

\author{
Anthony M Ciabarra, Mitchell S Elkind, James K Roberts, Randolph S Marshall
}

\begin{abstract}
Stuttering is an uncommon presentation of acute stroke. Reported cases have often been associated with left sided cortical lesions, aphasia, and difficulties with other non-linguistic tests of rhythmic motor control. Three patients with subcortical lesions resulting in stuttering are discussed. In one patient the ability to perform time estimations with a computerised repetitive time estimation task was characterised.

One patient had a pontine infarct with clinical evidence of cerebellar dysfunction. A second patient had a left basal ganglionic infarct and a disruption of timing estimation. A third patient had a left subcortical infarct and a mild aphasia. These findings expand the reported distribution of infarction that can result in acquired stuttering. Subcortical mechanisms of speech control and timing may contribute to the pathophysiology of acquired stuttering.

(7 Neurol Neurosurg Psychiatry 2000;69:546-549)
\end{abstract}

Keywords: stuttering; stroke; subcortical; infarction

Stuttering has been defined as a disruption of the fluency of verbal expression characterised by the involuntary repetition or prolongation in the utterance of sounds and syllables. ${ }^{1}$ Acquired stuttering is infrequent after stroke. Evidence for the physiological basis of stuttering has come from findings of acquired stuttering in adults after vascular lesions or traumatic lesions, as well as from studies of developmental stutterers. Most cases of acquired stuttering with stroke are reported to result from left cortical or bilateral cortical lesions with associated aphasia. $^{23}$ Subcortical stroke leading to acquired stuttering has been infrequently reported in the literature. We present three cases of acquired stuttering resulting from subcortical infarction and investigate the timing behaviour of one patient, using a computerised repetitive time estimation task.

Correspondence to: Dr Randolph S Marshall ciabarr@

cpmc.cpmc3.columbia.edu

Received 3 December 1999 and in revised form

6 April 2000

Accepted 20 April 2000

\section{Methods}

Three cases of acquired stuttering were evaluated with brain MRI. A computerised repetitive time estimation task was performed with patient 2 and in normal control subjects. Patients were instructed to repetitively press a mouse button in a target interval of 10 to 13 seconds from the prior response. After each response, one of two tones was sounded to indicate whether the response was inside or outside of the target interval. Testing was performed in three blocks of 18 intervals each.

\section{Results}

PATIENT 1

A 53 year old right handed man with a history of diabetes and hypertension presented with a 2 day history of episodic vertigo and ataxia. On examination he had a left internuclear opthalmoplegia, dysarthria, left facial droop, jaw tremor, right dysmetria, and gait ataxia. Cognition and swallowing were normal. Language function disclosed stuttering consisting of rapid speech with consistent repetition of every syllable with intermittent aphonia but no initial prolongations. Stuttering was present on spontaneous speech and with repetition. He showed intermittent velopharyngeal incompetency during connected speech utterances. He was able to decrease the frequency of his stuttering by speaking slowly. Brain MRI showed a linear band of T2 signal hyperintensity in the left rostromedial pons consistent with small vessel infarction (fig $1 \mathrm{~A}$ ).

\section{PATIENT 2}

A 54 year old right handed woman with a history of diabetes, hypertension, myocardial infarction, and breast and ovarian cancer awoke with dysarthria. On examination her spontaneous speech, reading, and repetition were slow but grammatically correct with initial prolongations of consonants and occasional repetitions of initial syllables without circumlocutions. Cognitive function was intact. A mild, right facial droop and slowness of right finger movements with preserved strength were noted. Otherwise motor, sensory, and cerebellar examinations were normal. A computerised test of timing behaviour ${ }^{4}$ showed impaired ability to make accurate time estimations (fig 2). T2 weighted brain MRI demonstrated infarction in the left putamen extending to the caudate and corona radiata (fig $1 \mathrm{~B}$ ).
PATIENT 3

A 63 year old left handed woman with a history of hypertension and hypercholesterolaemia 

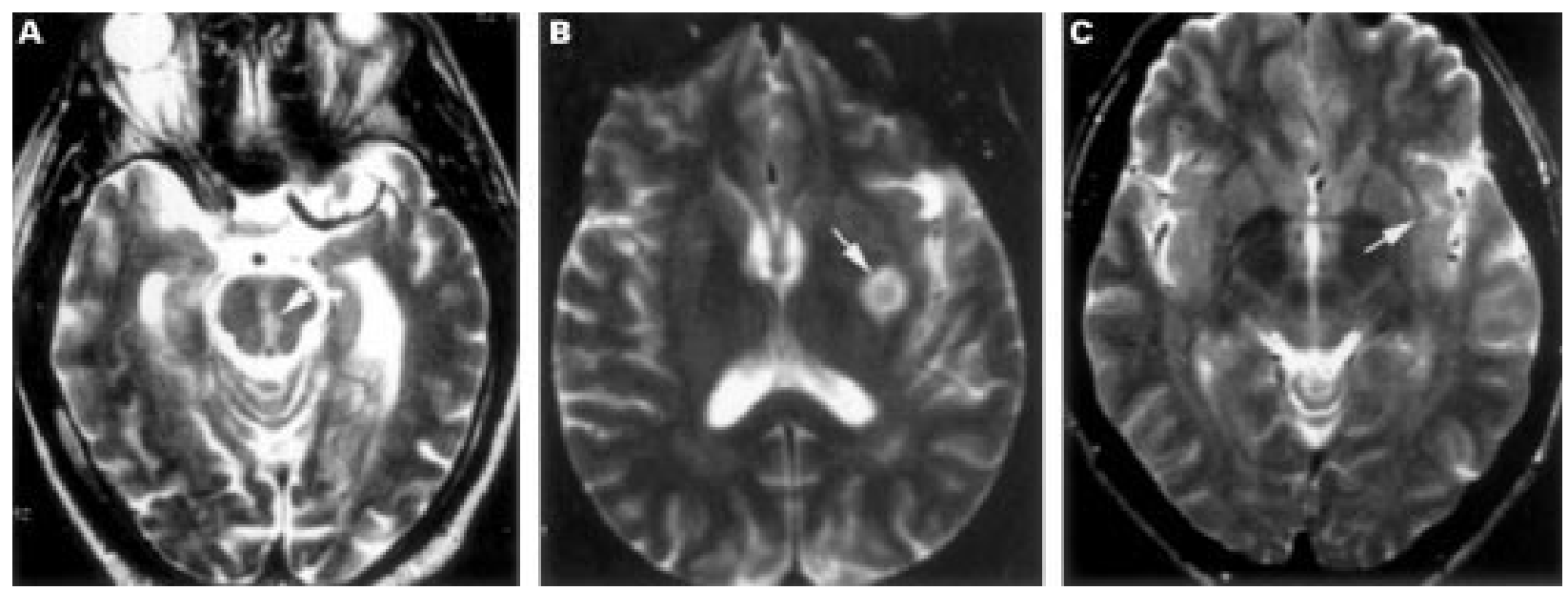

Figure 1 (A) T2 weighted brain MRI of patient 1 showing signal abnormality consistent with infarction in the left rostromedial pons. (B) T2 weighted brain MRI of patient 2 showing signal abnormality in the left putamen, corona radiata, and caudate, consistent with infarction. (C) T2 weighted brain MRI of patient 3 showing a small subcortical infarct in the left corona radiata and a small left lateral putamen and subinsular infarct.
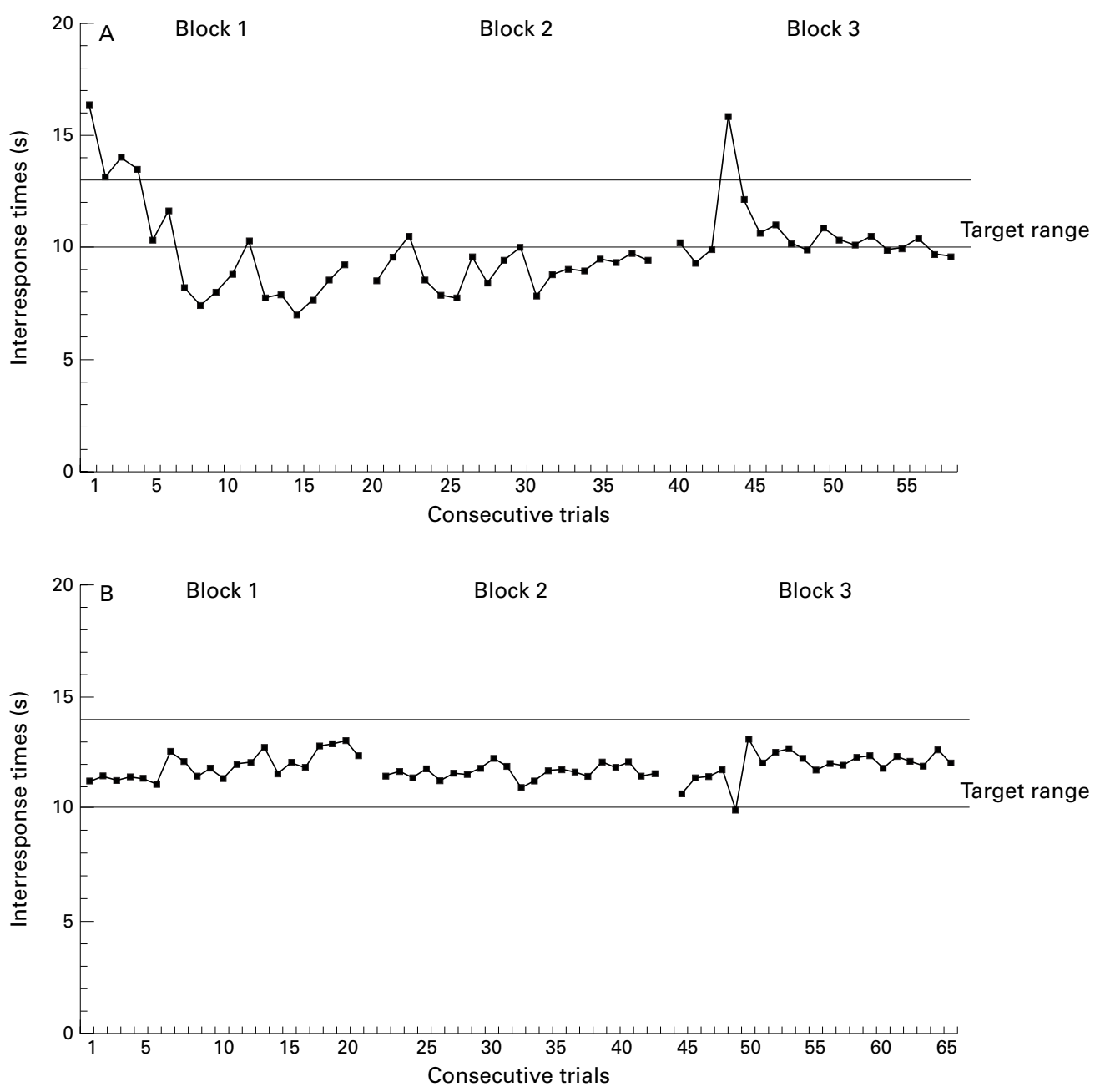

Figure 2 Computerised repetitive time estimation task in (A) patient 2 and in (B) a normal control subject.

experienced a sudden onset of a change in vision, right hand weakness, and difficulty finding words. On examination her comprehension, reading, and writing were intact. Stuttering consisted of repetition of initial syllables during spontaneous speech with occasional initial prolongations. Transcranial Doppler showed increased flow velocities in both middle cerebral arteries. Brain MRI disclosed a small subcortical infarct in the left corona radiata and a small left lateral putamen and subinsular infarct.

\section{Discussion}

Although most reported cases of acquired stuttering result from left cortical or bilateral cortical lesions with associated aphasia ${ }^{2}{ }^{3}$ (table), the cases we present here show that acquired 
Reported cases of acquired stuttering after stroke with brain imaging available

\begin{tabular}{ll}
\hline Reference & Location of stroke \\
\hline Helm et al $1978^{2}$ & Right frontal-perisylvian \\
& No lesion \\
& No lesion \\
& Left frontoparietal \\
& Left frontal \\
& Right parietal \\
Rosenbek et al $1978^{3}$ & Left frontal, temporal, parietal, occipital \\
& Left temporoparietal \\
& Left frontotemporal \\
& Bilateral diffuse \\
& Left frontoparietal \\
Donnan $1979^{5}$ & No lesion \\
& No lesion \\
Rosenfield et al $1980^{6}$ & Right medial, anterior frontal \\
Ardila and Lopez $1986^{7}$ & Right temporal \\
Fleet and Heilman $1989^{8}$ & Right frontoparietal watershed \\
Soroker et al $1990^{9}$ & Right subcortical \\
Abe et al $1993^{10}$ & Bilateral medial thalami and midbrain \\
Lanoe et al $1994^{11}$ & Left centrum semiovale \\
Kono et al $1998^{12}$ & Left striatocapsular \\
Grant et al $1999^{13}$ & Left frontotemporoparietal \\
& Medial left occipital \\
\hline
\end{tabular}

stuttering may also result from infarction in subcortical structures including the pons. A pontine infarct as seen in our first patient has not been previously reported to result in acquired stuttering. The persistence of this patient's stuttering on every syllable sets him apart from our other two patients. A patient with bilateral thalamic and midbrain infarcts was reported to show a repetitive speech disorder similar to stuttering. ${ }^{10}$ This case was notable for a high number of repetitions of syllables. The authors concluded that as the clinical features of their patient's stuttering were similar to the stuttering of patients with infarcts of the supplementary motor area, thalamic and midbrain projections to the supplementary motor area may have been disrupted. Additionally, alleviation of acquired stuttering with thalamic stimulation has led to the suggestion that the brainstem reticular formation, diencephalon, and basal ganglia are involved in the motor execution of speech through their projections to the frontal cortex. ${ }^{14} 15$ We propose that disruption of connections from the brainstem reticular formation to the supplementary motor area in our first patient may have resulted in acquired stuttering.

Studies with PET and SPECT, focusing primarily on developmental stutterers, have implicated multiple neural mechanisms in the generation of stuttering. ${ }^{16-20}$ These neural mechanisms include a widespread overactivation of the motor systems in both the cerebral and cerebellar hemispheres with a right predominance, a lack of normal activation of the left, anterior, superior temporal phonological circuits, and a deactivation of a circuit between the left frontal and temporal cortex. ${ }^{19}$ However, studies in developmental stutterers have also suggested that subcortical structures may play a part in stuttering. Brain PET studies of developmental stutterers have showed left caudate hypometabolism during stuttering and fluent choral reading. ${ }^{20}$ It is important to be cautious when attempting to infer analogous mechanisms from studies of developmental stutterers as they do not have structural brain lesions and a recent study did not show consistent differences in blood flow at rest compared with controls. ${ }^{21}$

Other mechanisms have been proposed for the generation of acquired stuttering with subcortical infarcts. These include impaired regulatory callosal transmission, ${ }^{9}$ damage to circuits connecting the basal ganglia to the cortex, ${ }^{12}$ and also cortical dysfunction resulting from subcortical infarction. ${ }^{11}$ The last hypothesis was substantiated in one patient with a left striatocapsular infarction by showing cortical deactivation visualised on SPECT imaging. ${ }^{11}$ In our second and third patients, it is possible that intrahemispheric connections were disrupted by the extension of the lesion into the subcortical white matter. Alternatively, lesions of the left basal ganglia in these two patients may have led to stuttering independent of disruption of intrahemispheric connections.

Difficulty with non-linguistic skilled motor tasks has been described in patients with acquired stuttering, including difficulty with rhythmic tapping and copying three dimensional figures. ${ }^{22} 23$ Our second patient demonstrated marked impairment of repeated time estimations. Disruption of the timing of speech control may play a part in generating stuttering.

Multiple mechanisms may exist which can generate acquired stuttering given the diversity of lesions that have been described. Our three patients expand the localisation of lesions that can result in acquired stuttering and show that subcortical mechanisms of speech control and timing may contribute to the pathophysiology of acquired stuttering.

This research was made possible in part by the Doris and Stanley Tananbaum Foundation.

1 Wingate ME. A standard definition of stuttering. $\mathcal{F}$ Speech Hear Disord 1964;29:484-9.

2 Helm NA, Butler RB, Benson FD. Acquired stuttering. Neurology 1978;28:1159-65.

3 Rosenbek J, Messert B, Collins M, et al. Stuttering following brain damage. Brain Lang 1978;6:82-96.

4 Lazar RM, Marshall RS, Pile-Spellman J, et al. Continuous time estimation as a behavioural index of human cerebral ischaemia during temporary occlusion of the internal carotid artery. 7 Neurol Neurosurg Psychiatry 1996;60:55963.

5 Donnan GA. Stuttering as a manifestation of stroke. Med $\mathcal{F}$ Aust 1979;1:44-45.

6 Rosenfield DG, Miller SD, Feltovich M. Brain damage causing stuttering. Trans Am Neurol Assoc 1980;105:1-3.

7 Ardila A, Lopez MV. Severe stuttering associated with right hemisphere lesion. Brain Lang 1986;27:239-46.

8 Fleet W, Heilman K. Acquired stuttering from a right hemisphere lesion in a right-hander. Neurology 1985;35:1343-6.

9 Soroker N, Bar-Israel Y, Schechter I, et al. Stuttering as a manifestation of right-hemispheric subcortical stroke. Eur Neurol 1990;30:268-70.

10 Abe K, Yokoyama R, Yorifuji S. Repetitive speech disorder resulting from infarcts in the paramedian thalami and midresulting from infarcts in the paramedian thalami and
brain. F Neurol Neurosurg Psychiatry 1993;56:1024-6.

11 Lanoe Y, Pedetti L, Lanoe A, et al. Aphasia caused by isolated lesion of the semi-ovale centre: contribution of the measurement of cerebral blood flow. Rev Neurol (Paris) 1994;150:430-4.

12 Kono I, Hirano T, Ueda Y, et al. A case of acquired stuttering resulting from striatocapsular infarction. Rinsho Shinkeigaku 1998;38:758-61.

13 Grant AC, Biousse V, Cook AA, et al. Stroke-associated stuttering. Arch Neurol 1999;56:624-7.

14 Bhatnagar SC, Andy OJ. Alleviation of acquired stuttering with human centremedian thalamic stimulation. 7 Neurol Neurosurg Psychiatry 1989;52:1182-4.

15 Andy OJ, Bhatnagar SC. Thalamic induced stuttering: (surgical observations). $\mathcal{F}$ Speech Hear Res 1992;34:796-800.

16 Wood F, Stump D, McKeehan A, et al. Patterns of regional Wood F, Stump D, McKeehan A, et al. Patterns of regional
cerebral blood flow during attempted reading aloud by stutterers both on and off haloperidol medication: evidence for inadequate left frontal activation during stuttering. Brain Lang 1980;9:141-4. 
17 Pool KD, Devous MD Sr, Freeman FJ, et al. Regional cerebral blood flow in developmental stutterers. Arch Neucerebral blood flow in $1991 ; 48: 509-12$.
rol

18 Wu JC, Maguire G, Riley G, et al. A positron emission tomography $\left[{ }^{18} \mathrm{~F}\right]$ deoxyglucose study of developmental stuttering. Neuroreport 1995;6:501-5.

19 Fox PT, Ingham RJ, Ingham JC, et al. A PET study of the neural systems of stuttering. Nature 1996;382:158-62.

20 Wu JC, Maguire G, Riley G, et al. Increased dopamine activity associated with stuttering. Neuroreport 1997;8:767-70.
21 Ingham RJ, Fox PT, Ingham JC, et al. Functional-lesion investigation of developmental stuttering with positron emission tomography. F Speech Hear Res 1996;39:120827

22 Cooper MH, Allen GD. Timing control accuracy in normal speakers and stutterers. F Speech Hear Res 1977;20:55-71.

23 Hand CR, Haynes WO. Linguistic processing and reaction time differences in stutterers and nonstutterers. F Speech time differences in stutte
Hear Res $1983 ; 26: 181-5$. 